\title{
STRUCTURE AND PROPERTIES \\ OF BRAIDED SLEEVE PREFORMS \\ FOR CHEMICAL VAPOR INFILTRATION
}

Thomas L. Starr, Odile G. Fiadzo and Nicole Hablutzel

April 1998

$\begin{array}{cc}\text { Report prepared by } & \text { APR } 161998 \\ \text { School of Materials Science and Technology } & \text { O ST I }\end{array}$

$\begin{array}{cc}\text { Report prepared by } & \text { APR } 161998 \\ \text { School of Materials Science and Technology } & \text { O ST I }\end{array}$

RECEIVED

Georgia Institute of Technology

Atlanta, Georgia 30332

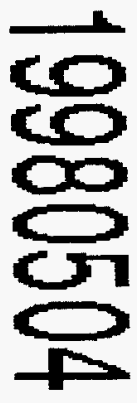

Oak Ridge National Laboratory

Oak Ridge, Tennessee 37831

managed by

Lockheed Martin Energy Systems

for the

U.S. Department of Energy

DTIC QUAJITY IRTSPECTED

under Contract No. DE-AC05-84R21400

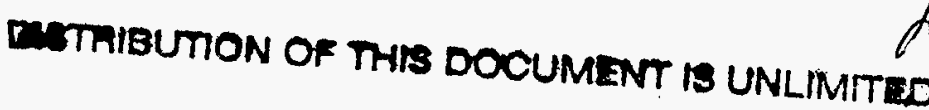


This report has been reproduced directly from the best available copy.

Available to DOE and DOE contractors from the Office of Scientific and Technical Information, P.O. Box 62, Oak Ridge, TN 37831; prices available from (423) 576-8401.

Available to the public from the National Technical Information Service, U.S. Department of Commerce, 5285 Port Royal Rd., Springfield, VA 22161.

This report was prepared as an account of work sponsored by an agency of the United States Government. Neither the United States Government nor any agency thereof, nor any of their employees, makes any warranty, expressed or implied, or assumes any legal liability or responsibility for the accuracy, completeness, or usefulness of any information, apparatus, product, or process disclosed, or represents that its use would not infringe privately owned rights. Reference herein to any specific commercial product, process, or service by trade name, trademark, manufacturer, or otherwise, does not necessarily constitute or imply its endorsement, recommendation, or favoring by the United States Government or any agency thereof. The views and opinions of authors expressed herein do not necessarily state or reflect those of the United States Government or any agency thereof. 


\section{STRUCTURE AND PROPERTIES OF BRAIDED SLEEVE PREFORMS FOR CHEMICAL VAPOR INFILTRATION}

Thomas L. Starr, Odile G. Fiadzo and Nicole Hablutzel

April 1998

Research sponsored by the U.S. Department of Energy,

Fossil Energy

Advanced Research and Technology Development Materials Program

Report prepared by

School of Materials Science and Engineering

Georgia Institute of Technology

Atlanta, Georgia 30332

under

Subcontract 19X-00184

for

Oak Ridge National Laboratory

Oak Ridge, Tennessee 37831

managed by

Lockheed Martin Energy Systems

for the

U.S. Department of Energy

under Contract No. DE-AC05-84R21400 


\section{INTRODUCTION}

In all composites the properties and structure of the reinforcement strongly influence the performance of the material. For some composites, however, the reinforcement also affects the fabrication process itself exerting an additional, secondorder influence on performance. This is the case for the chemical vapor infiltration (CVI) process for fabrication of ceramic matrix composites ${ }^{1}$. In this process the matrix forms progressively as a solid deposit, first onto the fiber surfaces, then onto the previous layer of deposit, ultimately growing to fill the inter-fiber porosity. The transport of reactants to the surfaces and the evolved morphology of the matrix depend on the initial reinforcement structure. This structure can vary greatly and is controlled by such factors as fiber size and cross-section, the number of filaments and amount of twist per tow or yarn, and the weave or braid architecture. Often the choice of reinforcement is based on mechanical performance analysis or on the cost and availability of the material or on the temperature stability of the fiber. Given this choice, the composite densification process - CVI - must be optimized to attain a successful material.

Ceramic fiber in the form of cylindrical braided sleeve is an attractive choice for fabrication of tube-form ceramic matrix composites. Multiple, concentric layers of sleeve can be placed over a tubular mandrel, compressed and fixed with a binder to form a freestanding tube preform. This fiber architecture is different than that created by layup of plain-weave cloth - the material used in most previous CVI development. This report presents the results of our investigation of CVI densification of braided sleeve preforms and the evolution of their structure and transport properties during processing.

\section{BACKGROUND}

The evolution of structure and the variation of transport properties during CVI

\footnotetext{
Research sponsored by the U.S. Department of Energy, Fossil Energy Advanced Research and Technology Development Materials Program, DOE/FE AA 1510 10 0, Work Breakdown Structure Element GT-I
} 
densification are not independent phenomena but rather are strongly interrelated. The pore structure controls the vapor phase transport of the reactants and this transport, in turn, influences the growth of the solid matrix and the evolution of the pore structure. For an inhomogeneous material - such as a composite or a porous material - structure and transport properties can be presented as average or "effective" properties of a representative volume element (RVE) over which the material is considered homogeneous. This assumption simplifies analysis and representation of these materials and is the basis of many analytical and numerical methods for performance or process simulation. Thus, we assume that the CVI preform and partially densified composite can be represented - over some length scale - as a homogeneous material with such properties as fraction porosity, pore surface area, gas permeability and effective diffusion coefficient and that these properties are based on a suitably averaged underlying microstructure which evolves during processing.

\section{Structure Evolution in CVI}

The problem of structure evolution in CVI is part of the more general topic of microstructure development in materials processing. Much work has been done for processes such as solidification or crystallization where the solid phase forms by growth from nuclei in a liquid or amorphous phase. The most common approach is based on the Avrami equation for growth of randomly centered, overlapping spheres ${ }^{2}$. This relation is based on the assumption that the ratio of incremental volume of solid actually formed to incremental volume of solid that would be formed without overlap is equal to the fraction porosity. This simple relation produces an exponential approach to full density as the radius of the spheres increases indefinitely. The Avrami approach has been extended to CVI densification of fibrous preforms both as growth of randomly centered, parallel, overlapping cylinders ${ }^{3}$ or as shrinkage of cylindrical capillaries ${ }^{4}$.

In the Avrami model the structure approaches full density as the radius of the growing "particles" approaches infinity, i.e. there is no distinct end to growth and no residual porosity. In fact, however, the CVI process does have a distinct end point at 
which no further deposition occurs and composites "completely" densified by the CVI process may contain from 5 to $20 \%$ residual, inaccessible porosity. The amount and structure of this porosity depends on the initial fiber architecture. Yu and Sotirchos ${ }^{5}$ proposed a generalized pore model for gas-solid reactions based on an interconnected network of cylindrical pores with a distribution of diameters. Percolation theory is used to predict creation of trapped porosity as density increases and the smaller pores are filled. While this approach has many desirable features, the structure model employed does not relate well to the anisotropic, woven fiber structures commonly used for CVI preforms.

A more recent model for the microstructure of woven fiber preforms and composites is based on a node-bond model ${ }^{6}$. In this model the porosity is represented as a network of spherical "nodes" connected by cylindrical "bonds". The network geometry is directly related to the regular structure of the woven preform. The spatial arrangement of the nodes and their coordination number (number of nearest neighbors) is fixed by the weave architecture i.e. tow spacing and weave or braid pattern. Values of the node and bond diameters exhibit a distribution of values around an average which is set to match the overall volume fraction of inter-tow porosity.

\section{Transport Properties of Porous Materials}

Studies of gas (and more, generally, fluid) transport through porous media and models for this transport have been reported in the literature over many years and in many technical areas ${ }^{7,89}$. Such transport is fundamental in fields as diverse as gas filtration, heterogeneous catalysis, pollutant migration, resin transfer molding of polymer composites and coal gasification. While some of this work is applicable to mass transport during CVI processing, much is not, due to the special characteristics of this process for fabrication of dense composites. For example while models for gas permeability of fibrous filters are well developed ${ }^{10}$ many of these are limited to materials with randomly oriented fibers at low volume fraction. In contrast a typical CVI preform has fibers arranged in an anisotropic, bimodal pattern at a volume fraction near $40 \%$. In addition, the evolution of the transport properties of this compact as the density increases is a critical factor in the 
process.

The node-bond model described above for CVI preforms and composites also yields an estimate of mass transport ${ }^{6}$. Describing the porosity as a percolating network of nodes and bonds, this model predicts the dependence of permeability on density during CVI infiltration. The gas permeability of this network is calculated assuming Poiseuille flow through the cylindrical bonds with a distribution of diameters. Densification is simulated by incrementally reducing the bond and node dimensions and recalculating the network pore volume, surface area and permeability. As densification proceeds the smaller bonds close and as the fraction of open bonds approaches the percolation limit the accessible pore fraction and the network permeability both vanish exponentially.

The structure and transport models discussed above provide a basis for understanding composite evolution during CVI densification. The experimental efforts described below are designed to characterize this evolution for braided sleeve preforms and to provide data needed to develop accurate predictive models for structure and transport property development. Such models will allow evaluation and optimization of CVI processing for densification of these preform structures.

\section{EXPERIMENT}

Experimental efforts have coordinated with and supported CVI process development at Oak Ridge National Laboratory (ORNL) ${ }^{11}$. The materials tested are based on their potential for use as preforms for tube-shaped composites. Our characterization includes measurements of microstructure and gas permeability of preforms and partially infiltrated composites.

\section{Materials}

Preform and composite materials are fabricated from Nextel 312 (3M Company, St. Paul, MN) fibers by lay-up of braided cloths or sleeve materials (Figure 1). Nextel 312 
is a boria alumina silicate fiber with an oblong cross-section, an equivalent circular diameter of 10-12 $\mu \mathrm{m}$ and a density of $2.70 \mathrm{~g} / \mathrm{cm}^{3}$. Nextel biaxial braid is standard, commercially available "2-1/2 inch ID sleeve" material formed by a continuous braiding process. Triaxial braids are developmental materials provided in sleeve form by $3 \mathrm{M}$.

A schematic representation of the two braid forms is shown in Figure 2. Each can be characterized by "picks per inch" (ppi) - a measure of the yarn spacing - and by braid angle. Both braids are formed as continuous sleeve material. The diameter of this sleeve can be changed by stretching and compressing the sleeve in the axial direction although stretching is limited by the axial yarn for the triaxial braid. (The axial yarn in the triaxial braid is much finer than the bias yarns. It is difficult to see in Figure 1 but can be discerned in the 7 ppi braid.) The "picks-per-inch" and braid angle depend on the diameter and these are specified by the manufacturer based on a nominal diameter for the sleeve. The biaxial braid is specified as $9.5 \mathrm{ppi}$ at 2-1/2 inch ID. Three triaxial braids are specified as 11 and 9 ppi at 2 inch ID, and 7 ppi at 1-3/4 inch ID.

CVI preforms formed from these braids consist of several layers of cloth stacked with all layers in the same orientation. For disk specimens Nextel "cloths" were prepared by slitting the cylindrical sleeves lengthwise and flattening, maintaining the braid angle observed at the nominal sleeve diameter. Tube preforms were prepared (by ORNL) by placing successive sleeves over a mandrel, compressing and fixing in position with a phenolic binder. Composite test specimens were cut using a diamond saw from disks and tubes partially infiltrated at ORNL as listed in Table 1. 


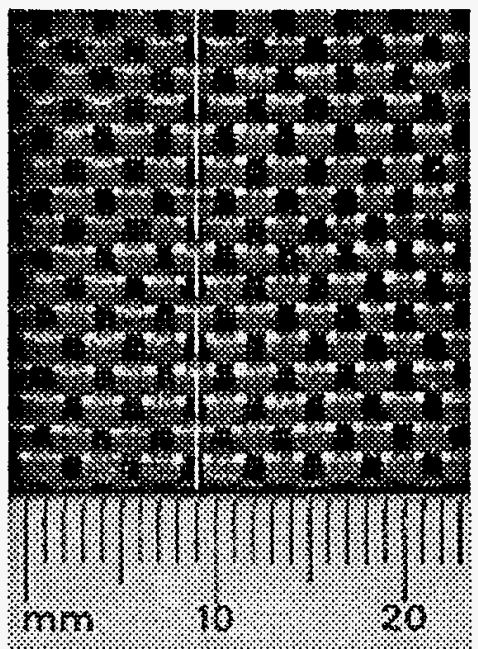

Nicalon plain weave

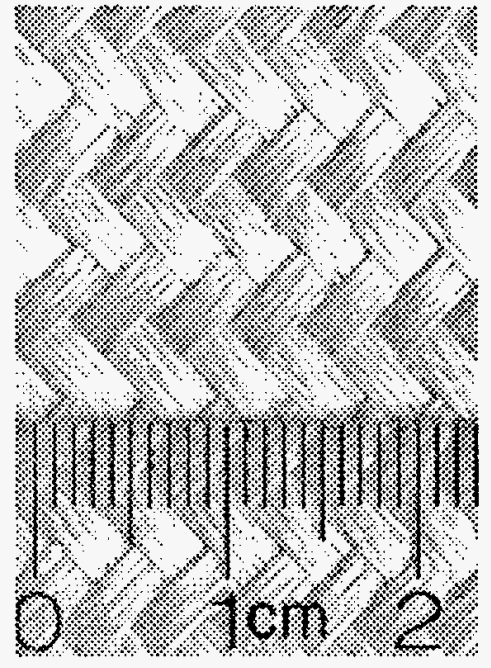

Nextel biaxial braid

2-1/2 ID sleeve

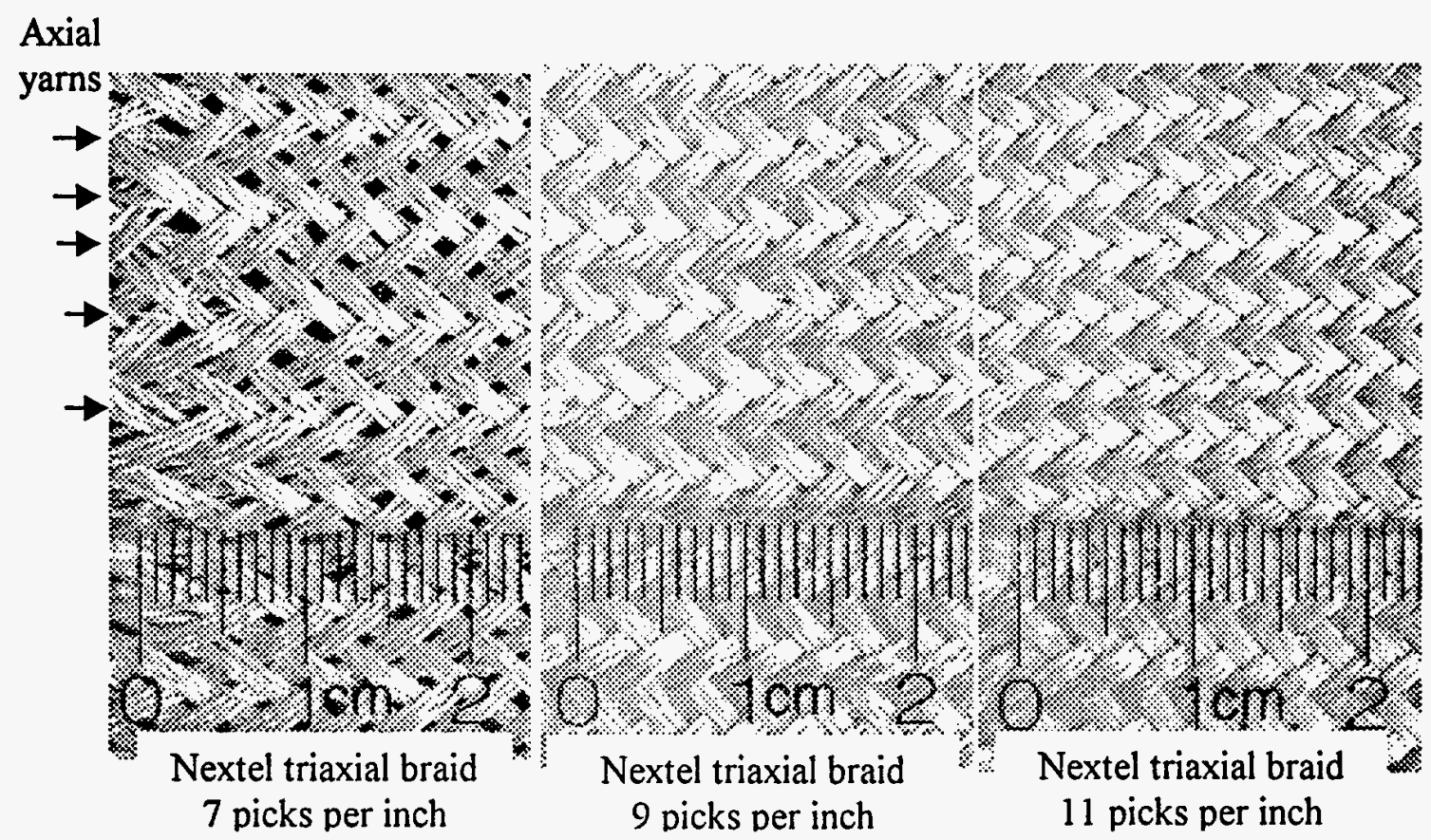

Figure 1. Nicalon plain weave and Nextel braids used for tube preforms and for our measurements. 


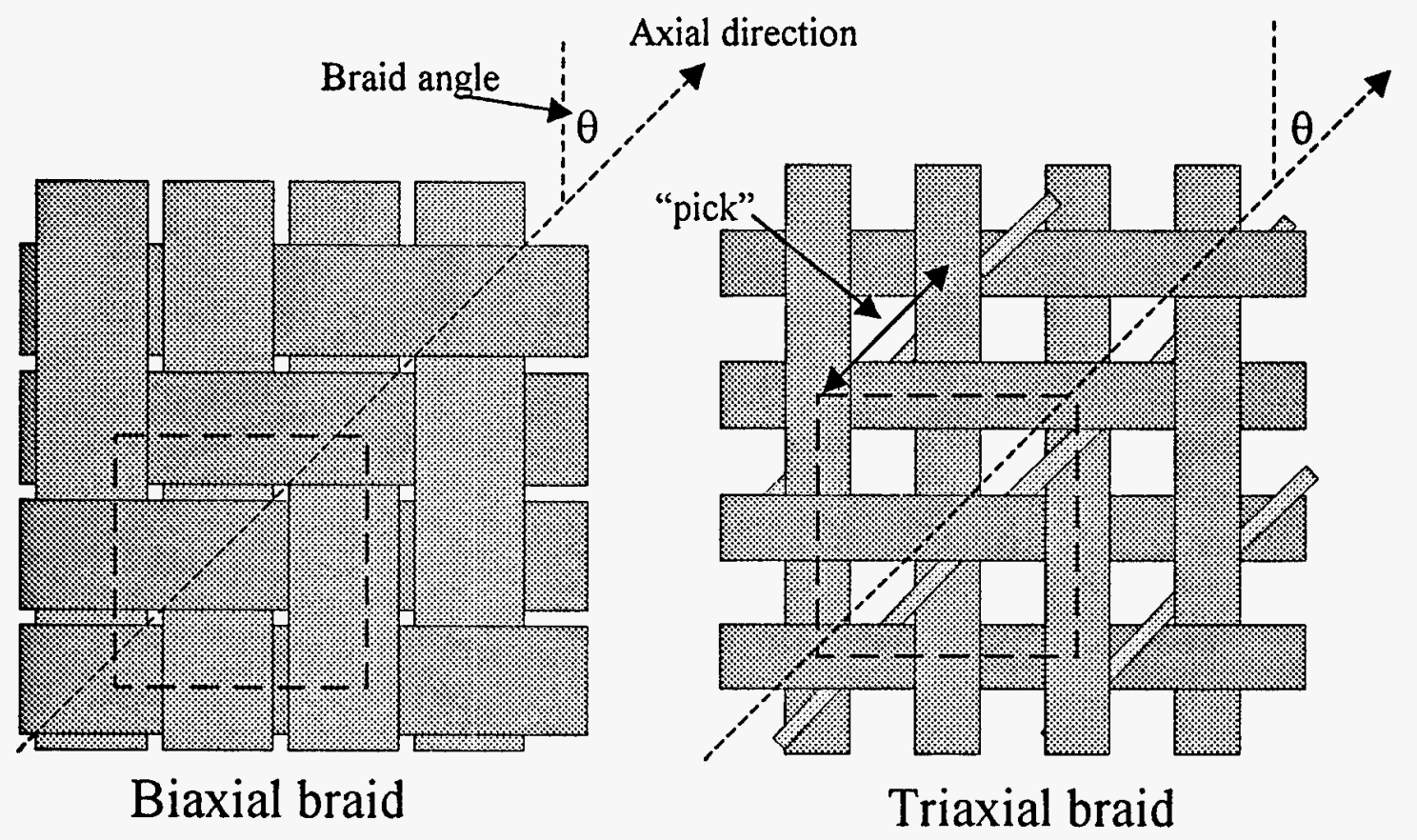

Figure 2. Schematic of biaxial and triaxial braid structures. Yarn in axial direction in triaxial braid is different filament and filament count than bias yarns. 
Table 1. Infiltrated composite materials used for characterization.

$$
\text { ORNL }
$$

\begin{tabular}{|c|c|c|c|}
\hline Fiber & Weave or braid & designation & Comments \\
\hline Nicalon & Plain weave & -- & $\begin{array}{l}\text { Tube, cloth wrapped onto graphite } \\
\text { mandrel; infiltrated } 6 / 95\end{array}$ \\
\hline Nextel & Biaxial braid (1-1/2") & $3 \mathrm{M} 1$ & Disk, 22 layers, infiltrated $19 \mathrm{hrs}$ \\
\hline Nextel & Biaxial braid (2-1/2") & CVI 1084 & Disk, 22 layers, infiltrated $5 \mathrm{hrs}$ \\
\hline Nextel & Biaxial braid (2-1/2") & CVI 1085 & Disk, 22 layers, infiltrated $10 \mathrm{hrs}$ \\
\hline Nextel & Biaxial braid (2-1/2") & CVI 1104 & Disk, 14 layers, infiltrated $5 \mathrm{hrs}$ \\
\hline Nextel & Biaxial braid (2-1/2") & CVI 1105 & Disk, 14 layers, infiltrated $10 \mathrm{hrs}$ \\
\hline Nextel & Biaxial braid (2-1/2") & CVI 1107 & Disk, 17 layers, infiltrated $5 \mathrm{hrs}$ \\
\hline Nextel & Biaxial braid (2-1/2") & CVI 1108 & Disk, 17 layers, infiltrated $10 \mathrm{hrs}$ \\
\hline Nextel & Triaxial braid $7 \mathrm{ppi}$ & CVI 1118 & Disk, 16 layers, infiltrated $5 \mathrm{hrs}$ \\
\hline Nextel & Triaxial braid $7 \mathrm{ppi}$ & CVI 1119 & Disk, 16 layers, infiltrated $10 \mathrm{hrs}$ \\
\hline Nextel & Triaxial braid $7 \mathrm{ppi}$ & CVI 1132 & $\begin{array}{l}\text { Tube, } 10 \& 14 \text { layers, } \\
\text { infiltrated } 28 \mathrm{hrs}\end{array}$ \\
\hline
\end{tabular}

\section{Measurement of Composite Microstructure}

The overall structure of these composites consists of "layers" of cloth and "channels" between these layers. Matrix material is deposited in the layers within the multi-filament tows and in the channels on the surfaces of the cloth layers. Our principal goal in characterizing these microstructures is to measure the thickness of this matrix as a function of position and to relate these measurements to matrix volume and composite density. 
The microstructure of infiltrated composites is characterized using specimens cut from a larger disk or tube composite, embedded in epoxy mounting material, polished and imaged with an optical microscope. Measurements include tow dimension and spacing, layer spacing and thickness of deposited matrix. Prior to mounting the apparent density of each specimen is determined from its dimensions and mass.

The composites are examined using a Reichert model MeF3A optical microscope. Each sample is examined first at low magnification $(20 \mathrm{X})$ in order to evaluate the overall structure and to select a region for detailed measurements. For these the specimen is examined at a higher magnification ( $80 \mathrm{X}$ or $160 \mathrm{X}$ ) and a series of micrographs obtained. The deposit thickness is measured at eight locations per channel. The measure is taken from the surface of a fiber located at the edge of the tow to the edge of the matrix layer. If the fiber tows are not precisely perpendicular to the surface of the polished sample then measurement is made in the direction for which deposit thickness is independent of the tow orientation, i.e normal to the cloth orientation. Care is taken to measure deposit thickness where the channel spacing is not too narrow. The criterion for the choice of a channel spacing minimum value is partial (still incomplete) filling of the channel, i.e. no overlap of matrix deposits from opposing each cloth layer. Average deposit thickness and standard deviation is calculated for each channel. An overall deposit thickness for each specimen also is calculated and related to the specimen density.

\section{Measurement of Gas Permeability}

The method and apparatus for measuring gas permeability has been described previously $^{12}$. The cylindrical specimen holder accepts a disk-shaped specimen up to $\mathbf{3 . 2}$ $\mathrm{cm}$ diameter and $3 \mathrm{~cm}$ thick (although specimens usually are considerably thinner than this). Rubber o-rings seal the top and bottom surfaces of the specimen. The bottom of the specimen holder is connected through a mass flowmeter to a regulated source of helium. Either of two flow meters $(0-20$ and $0-200 \mathrm{sccm})$ can be used. The two sides of a differential pressure (DP) gauge are connected above and below the specimen. The apparatus includes two different DP gauges $0-1.33 \mathrm{kPa}(0-10$ torr) and $0-26.6 \mathrm{kPa}(0-200$ 
torr). The availability of flow and DP gauges in both high and low ranges, and the capability of mounting specimens of various sizes combine to allow permeability measurements over the range from several hundred darcies to less than a hundredth of one darcy.

The specimen mounting method depends on the type of material tested. Specimens of infiltrated composite are cored from a larger tube or disk and mounted in a thick aluminum ring using epoxy cement. In most cases the cored specimens are cylinders with a diameter of $1.37 \mathrm{~cm}$ and height from 0.2 to $0.5 \mathrm{~cm}$. For preform measurements individual disks of cloth are cut to fit closely in an aluminum ring with $3.15 \mathrm{~cm}$ inside diameter. A specified number of layers are stacked to a height of $0.9 \mathrm{~cm}$ and held in place by two perforated aluminum lids.

\section{RESULTS AND DISCUSSION}

Microstructure and gas permeability measurements of preforms and partially infiltrated composites are reported below.

\section{Microstructure of Infiltrated Composites}

Typical micrographs for a partially infiltrated composite are shown in Figure 3. These reveal the overall layer-channel structure of the composite and the regularity of the matrix as it deposits on the original reinforcement structure. For this specimen the individual tows appear fully infiltrated and further densification would involve only deposition within channels.

Measurements of deposit thickness are plotted (Figure 4) as a function of channel position for this composite (CVI 1107) and for another composite with similar reinforcement architecture and longer infiltration time (CVI 1108). While there is considerable channel-to-channel variability in each material the overall average deposit thicknesses are different and relate to the infiltration time and overall density. Table 2 presents averaged data for each material examined. 

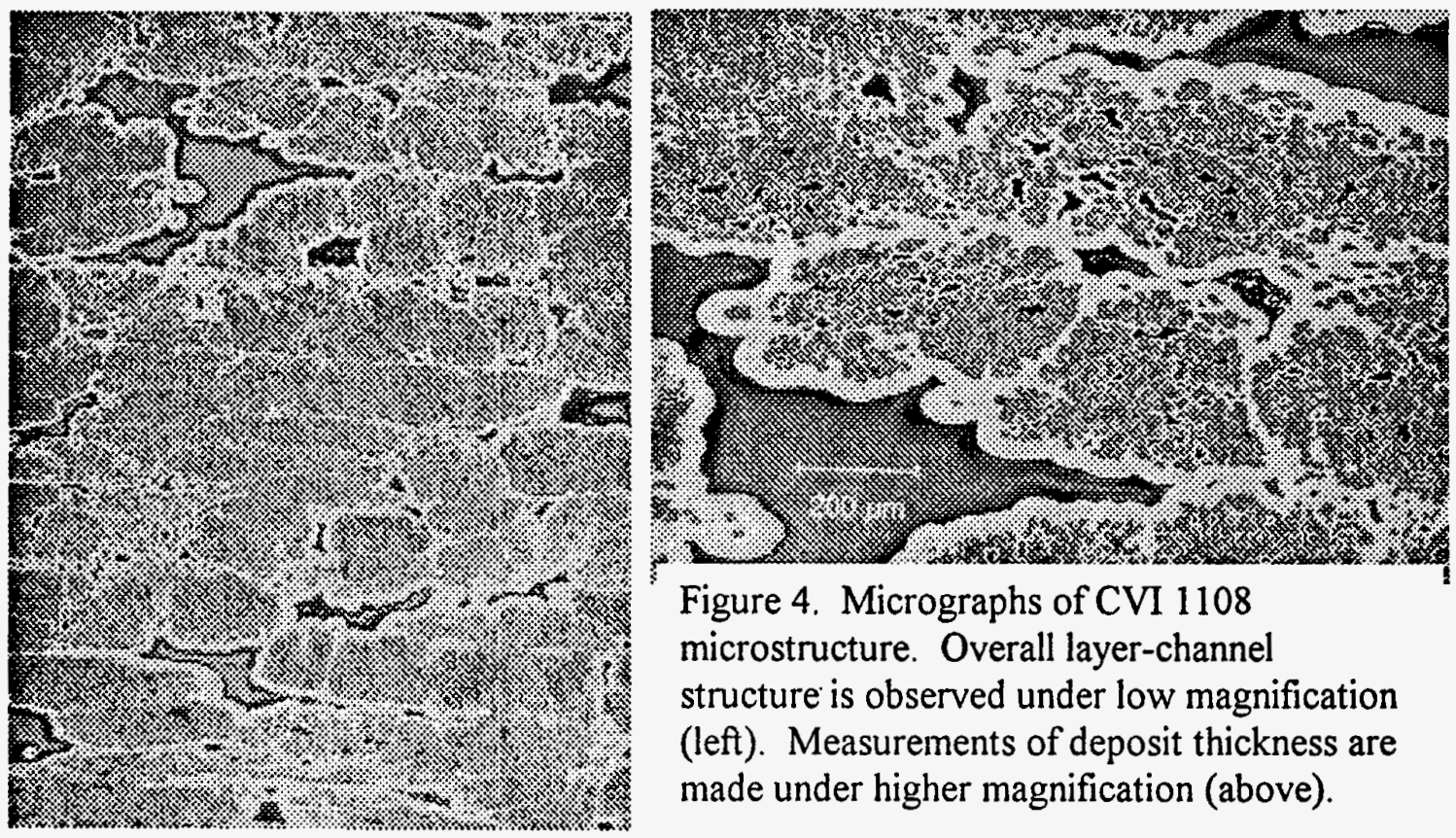

Figure 4. Micrographs of CVI 1108 microstructure. Overall layer-channel structure is observed under low magnification (left). Measurements of deposit thickness are made under higher magnification (above).

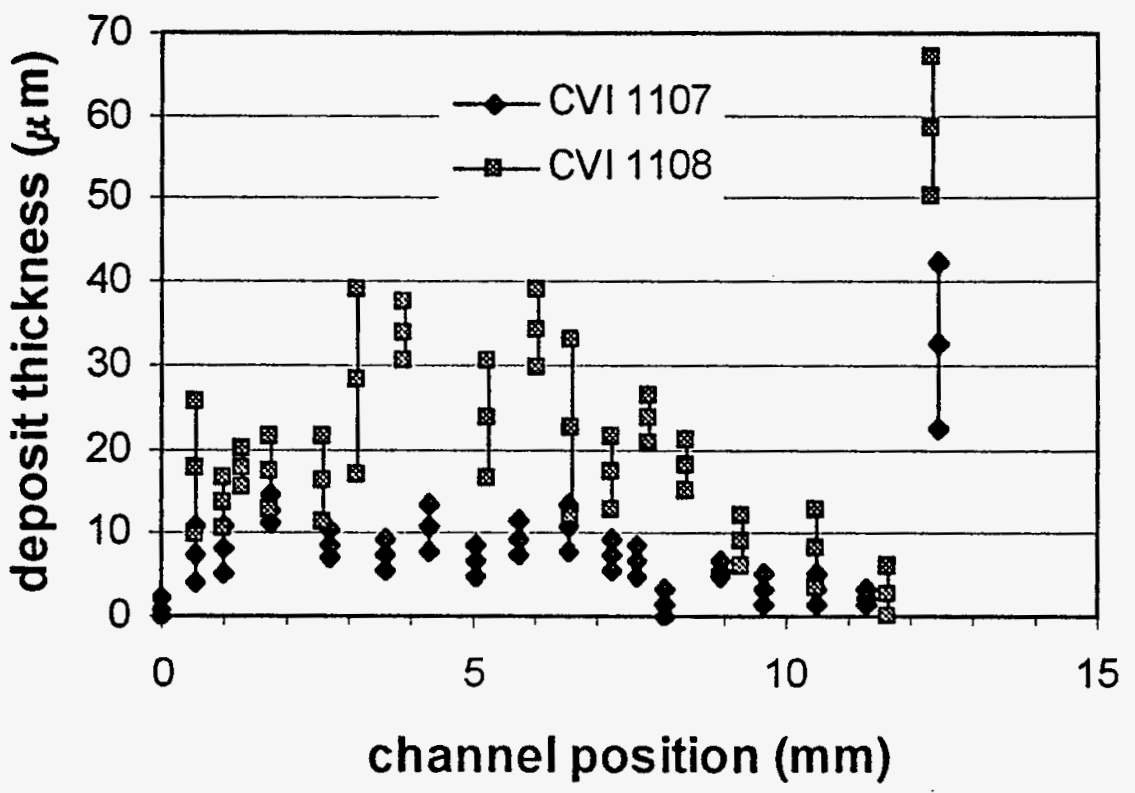

Figure 3. Deposit thickness measurements show increase with increasing infiltration time ( 5 hrs for CVI 1107 and 10 hours for CVI 1108. Channel position is measured from inlet end of disk specimens. 
Table 2. Average deposit thickness and density for each material examined. Density is expressed as volume fraction solid.

\begin{tabular}{cccc}
\hline $\begin{array}{c}\text { Material ID } \\
(\text { CVI xxxx })\end{array}$ & $\begin{array}{c}\text { Fiber } \\
(\% \mathrm{vol})\end{array}$ & $\begin{array}{c}\text { Deposit } \\
(\mu \mathrm{m})\end{array}$ & $\begin{array}{c}\text { Density } \\
(\% \mathrm{vol})\end{array}$ \\
\hline 1104 & 35 & 1.7 & 65.9 \\
1105 & 36 & 22.6 & 82.8 \\
1107 & 41 & 6.7 & 71.5 \\
1108 & 41 & 18.9 & 76.7 \\
1084 & 45 & 1.5 & 63.1 \\
1085 & 43 & 1.7 & 71.5 \\
& & & \\
1118 inlet & 31 & 11.6 & 51.0 \\
1119 & 31 & 27.1 & 55.6 \\
1132 outlet & 47 & 23.5 & 70.5 \\
1132 inlet & 46 & 33.0 & 76.1 \\
\hline
\end{tabular}

The materials in Table 1 represent the two types of Nextel braid with each braid examined at different preform fiber loading and at different degrees of infiltration. For example, CVI 1107 and 1108 represent the biaxial braid at $41 \%$ vol fiber at two stages of densification. The pairs CVI 1104/1105 and CVI 1084/1085 give densification behavior for the same braid at respectively 35 and $44 \%$ vol fiber loading. The pairs CVI 1118/1119 and CVI 1132 inlet/outlet represent densification the triaxial braid at 31 and $46 \%$ vol fiber loading. 
Gas Permeability of Preforms and Composites

Measured gas permeabilities for Nextel braid preforms and partially infiltrated composites are shown in Table 2 and in Figures 2-4. For preforms with comparable fiber loading the triaxial braid has a higher permeability than the biaxial braid, and both are higher than the Nicalon square weave cloth layup. Somewhat surprisingly the triaxial braids all give comparable results for comparable fiber loading, independent of the number of "picks per inch". Results for partially infiltrated composites are limited by the materials available. For the biaxial braids measurements include composites with three levels of fiber loading and densities up to $80 \%$ vol. For the triaxial braids results include only the 7 ppi material at one fiber loading and with only a small amount of infiltration; the highest density specimen measured is approximately $60 \%$ vol dense.

Measurements for biaxial braid (Figure 5) show the composite gas permeability decreases as density increases with permeability less than 0.5 darcy for all specimens more than 65\% dense. Not plotted are three additional specimens removed from CVI 1105 with densities between 75 and $83 \%$ vol that were found to be impermeable. These measurements suggest that the maximum achievable density for this preform leaves about $20 \%$ vol residual porosity. Beyond this point the pores are disconnected and will not support gas flow through the specimen. It is not clear whether this "percolation limit" varies with preform fiber loading; no firm conclusion can be drawn for our results using fiber levels between 35 and $45 \%$ vol. As expected the data is very "noisy" at high density. As a porous material approaches its percolation limit transport is dominated by a single, "critical" path. The resistance to flow along this path depends on its specific geometry and this is only weakly related to the bulk density.

Measurements for composites reinforced with triaxial braid are for the $7 \mathrm{ppi}$ material with a perform fiber loading of $31 \%$ vol and composite density up to $60 \%$ vol. At this point the gas permeability is still greater than 10 darcy. The percolation limit for this preform structure can not be determined from this data. 
Table 3. Gas permeability of layup preforms of Nextel braids.

\begin{tabular}{ccc}
\hline Cloth & $\begin{array}{c}\text { Volume } \\
\text { fraction }\end{array}$ & $\begin{array}{c}\text { Permeability } \\
\text { (darcy) }\end{array}$ \\
\hline Biaxial (2-1/2”) & 0.35 & 42 \\
“ & 0.41 & 22 \\
Triaxial 11 ppi & 0.31 & 132 \\
“ & 0.40 & 52 \\
Triaxial 9 ppi & 0.29 & 157 \\
“ & 0.40 & 46 \\
Triaxial 7 ppi & 0.33 & 148 \\
“ & 0.38 & 78 \\
\hline
\end{tabular}

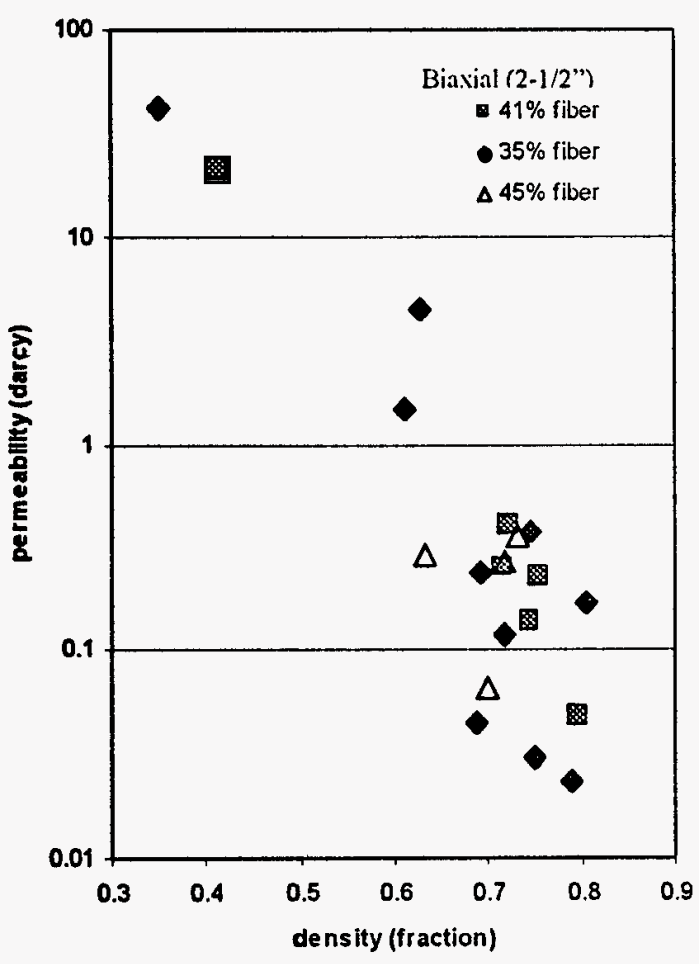

Figure 7. Permeability of biaxial braid preforms and composites.

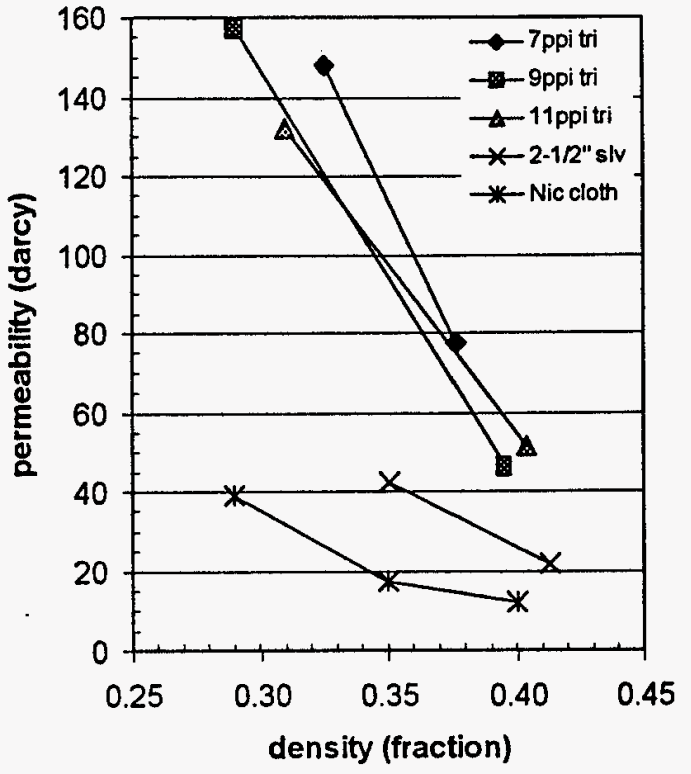

Figure 5 . Gas permeability of Nextel preforms is higher than for Nicalon plain weave cloth. (Nicalon data from ref. 12)

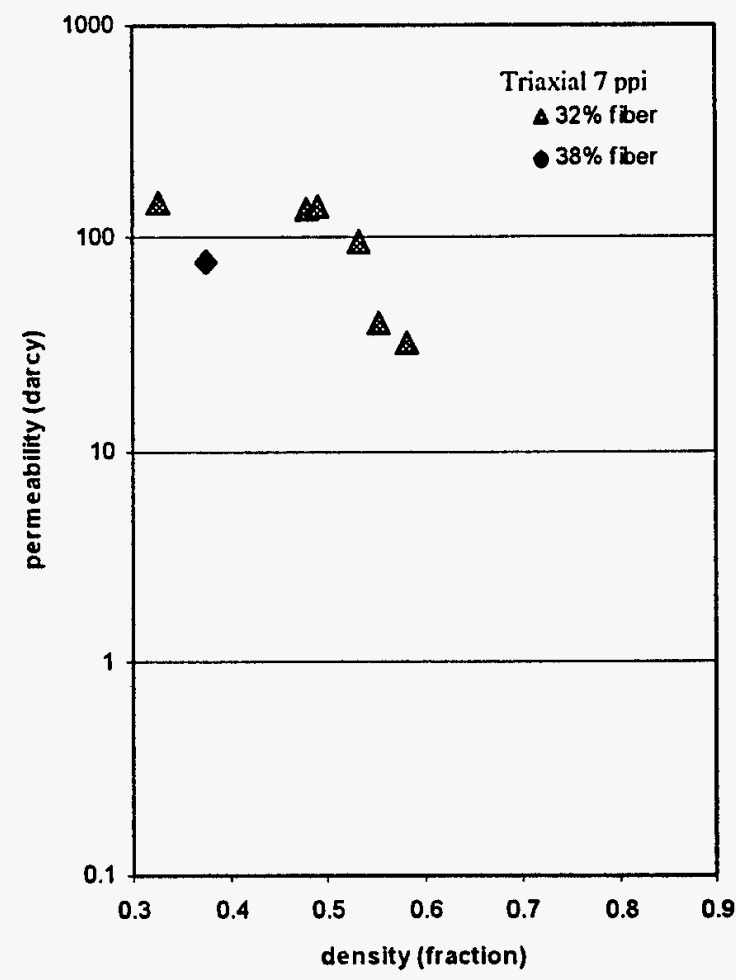

Figure 6. Permeability of triaxial braid 14 (7 ppi) preforms and composite. 


\section{CONCLUSION}

The densification behavior of braided sleeve preforms depends on the braid architecture and is significantly different than that of plain weave cloth layup preforms. "Full" densification of biaxial braid preforms produces a material with approximately $20 \%$ residual porosity which contrasts to plain-weave cloth layup preforms which can be densified to $5-8 \%$ residual porosity. Triaxial braids with smaller, more loosely spaced yarns provide better infiltration performance but the optimum architecture is not yet determined.

Characterization of these braided sleeve reinforced composites represents another step toward the ultimate goal of a predictive model for preform densification behavior based only on fiber geometry and architecture. Such a model would allow design or selection of preform architecture for good infiltration performance and, ultimately, enhance the performance of CVI fabricated composites. Additional investigation is needed to better characterize a critical element of this behavior - the approach to maximum density. The result of this stage of the densification process is the final composite. The amount and morphology of residual porosity in this material will play an important role in the performance of this ceramic matrix composite in critical high temperature applications.

\section{ACKNOWLEDGEMENT}

We gratefully acknowledge the contributions to this work by the CVI processing group at Oak Ridge National Laboratory directed by Dr. T. M. Besmann. In particular, Mr. K.J.Probst performed all of the preform layup and partial infiltration and provided these materials to us. We also acknowledge the assistance of Mr. R.G. Smith of 3M Company for providing the different braid materials. 


\section{REFERENCES}

${ }^{1}$ T.M. Besmann, B.W. Sheldon, R.A. Lowden and D.P. Stinton, "Vapor-Phase Fabrication and Properties of Continuous-Filament Ceramic Composites," Science 253, 1104 (1991)

${ }^{2}$ M. Avrami, "Kinetics of Phase Change, II. Transformation-Time Relations for Random Distribution of Nuclei," J. Chem. Phys. 8 , 212 (1940)

${ }^{3}$ R. P. Currier, "Overlap Model for Chemical Vapor Infiltration of Fibrous Yarns," J. Am. Ceram. Soc. $\underline{73}(8)$ 2274-80 (1990)

${ }^{4}$ S.V. Sotirchos, "Dynamic Modeling of Chemical Vapor Infiltration," AIChE Journal 37(9) 1365-1377 (1991)

${ }^{5}$ H-C Yu and S.V. Sotirchos, "A Generalized Pore Model for Gas-Solid Reactions Exhibiting Pore Closure," AlChE Journal 33(3) 382-393 (1987)

6 T.L. Starr, "Gas Transport Model for Chemical Vapor Infiltration," Journal of Materials Research 10(9) 1-7 (1995)

${ }^{7}$ R. A. Greenkorn, Flow phenomena in porous media : fundamentals and applications in petroleum, water, and food production, M. Dekker, New York, NY, 1983.

${ }^{8} \mathrm{~J}$. Bear and Y. Bachmat, Introduction to modeling of transport phenomena in porous media, Kluwer Academic Publishers, Boston, MA, 1990.

${ }^{9}$ F.A.L. Dullien, Porous media: fluid transport and pore structure, 2nd ed., Academic Press, San Diego, CA, 1992.

${ }^{10}$ J. Pich, "Gas Filtration Theory," pp. 2-153 in Filtration: Principles and Practices, C. Orr, ed., M. Dekker, New York, NY, 1987

${ }^{11}$ D.P Stinton, T.M. Besmann, W.M. Matlin, T.L. Starr and W.A. Curtin, "Forced Chemical Vapor Infiltration of Tubular Geometries: Modeling, Design, And Scale-Up" pp. 317-324 in Ceramic Matrix Composites-Advanced High-Temperature Structural Materials: Materials Research Society Symposium Proceedings vol. 365 (1995)

12 T.L. Starr and N Hablutzel, "Measurement of Gas Transport Through Fiber Preforms and Densified Composites for Chemical Vapor Infiltration," Journal of the American Ceramic Society, in press (1998) 
3M COMPANY

Ceramic Materials Department

201-4N-01 3M Center,

St. Paul, MN 55144

M. A. Leitheiser

\section{AIR PRODUCTS AND CHEMICALS}

P.O. Box 538

Allentown, PA 18105

S. W. Dean

\section{ALLISON GAS TURBINE DIVISION}

P.O. Box 420

Indianapolis, IN 46206-0420

P. Khandelwal (Speed Code W-5)

R. A. Wenglarz (Speed Code W-16)

AMA RESEARCH \& DEVELOPMENT CENTER 5950 McIntyre Street

Golden, CO 80403

T. B. Cox

\author{
ARGONNE NATIONAL LABORATORY \\ 9700 S. Cass Avenue \\ Argonne, IL 60439 \\ W. A. Ellingson \\ J. P. Singh
}

\section{BABCOCK \& WILCOX}

Domestic Fossil Operations

20 South Van Buren Avenue

Barberton, OH 44023

M. Gold

\section{BRITISH COAL CORPORATION}

Coal Technology Development Division

Stoke Orchard, Cheltenham

Glocestershire, England GL52 4ZG

J. Oakey

CANADA CENTER FOR MINERAL \& ENERGY TECHNOLOGY

568 Booth Street

Ottawa, Ontario

Canada KIA OGI

R. Winston Revic

Mahi Sahoo
DOE

DOE OAK RIDGE OPERATIONS

P.O.Box 2001

Oak Ridge, TN 37831

Assistant Manager for

Energy Research and Development

DOE

DOE OAK RIDGE OPERATIONS

P. O. Box 2008

Building 4500N, MS 6269

Oak Ridge, TN 37831

M. H. Rawlins

DOE

OFFICE OF BASIC ENERGY SCIENCES

Materials Sciences Division

ER-131

19901 Germantown Road

Germantown, MD 20874-1290

H. M. Kerch

DOE

IDAHO OPERATIONS OFFICE

P. O. Box 1625

Idaho Falls, ID 83415

J. B. Malmo

DOE

FEDERAL ENERGY TECHNOLOGY CENTER

3610 Collins Ferry Road

P.O. Box 880

Morgantown, WV 26507-0880

R. C. Bedick

D. C. Cicero

F. W. Crouse, Jr.

R. A. Dennis

N. T. Holcombe

W. J. Huber

T. J. McMalion

J. E. Notestein 


\section{DOE}

FEDERAL ENERGY TECHNOLOGY CENTER

626 Cochrans Mill Road

P.O. Box 10940

Pittsburgh, PA 15236-0940

A. L. Baldwin

G. V. McGurl

L. A. Ruth

T. M. Torkos

\section{DOE}

OFFICE OF FOSSIL ENERGY

FE-72

19901 Germantown Road

Germantown, MD 20874-1290

F. M. Glaser

\section{DOE}

OFFICE OF VEHICLE AND ENERGY R\&D

CE-151 Forrestal Building

Washington, DC 20585

R. B. Schulz

\section{DOW CORNING CORPORATION}

3901 S. Saginaw Road

Midland, MI 48686-0995

H. Atwell

EC TECHNOLOGIES

3614 Highpoint Drive

San Antonio, TX 78217

D. J. Kenton

\section{ELECTRIC POWER RESEARCH INSTITUTE}

P.O. Box 10412

3412 Hillview Avenue

Palo Alto, CA 94303

W. T. Bakker

J. Stringer

EUROPEAN COMMUNITIES JOINT RESEARCH CENTRE

Petten Establishment

P.O. Box 2

1755 ZG Petten

The Netherlands

M. Van de Voorde
GEORGIA INSTITUTE OF TECHNOLOGY

Materials Science \& Engineering (0245)

Bunger-Henry Building, Room 276

Atlanta, GA 30332-0245

T. L. Starr

IDAHO NATIONAL ENGINEERING \&

ENVIRONMENTAL LABORATORY

P. O. Box 1625

Idaho Falls, ID 83415

B. H. Rabin

\section{LAWRENCE LIVERMORE NATIONAL LABORATORY}

P.O. Box 808, L-325

Livermore, CA 94550

W. A. Steele

NATIONAL MATERIALS ADVISORY BOARD

National Research Council

2101 Constitution Avenue

Washington, DC 20418

K. M. Zwilsky

OAK RIDGE NATIONAL LABORATORY

P.O. Box 2008

Oak Ridge, TN 37831

T. M. Besmann

P. T. Carlson

J. M. Crigger (4 copies)

R. R. Judkins

R. A. Lowden

D. P. Stinton

M. R. Upton

OFFICE OF NAVAL RESEARCH

Code 431,800 N. Quincy Street

Arlington, VA 22217

S. G. Fishman

\section{SHELL DEVELOPMENT COMPANY}

WTC R-1371

P.O. Box 1380

Houston, TX 77251-1380

W. C. Fort 
TENNESSEE VALLEY AUTHORITY

Energy Demonstration \& Technology

MR2N58A

Chattanooga, TN 37402-2801

C. M. Huang

THE JOHNS HOPKINS UNIVERSITY

Materials Science \& Engineering

Maryland Hall

Baltimore, MD 21218

R. E. Green, Jr.

THE MATERIALS PROPERTIES COUNCIL, INC.

United Engineering Center

345 E. Forty-Seventh Street

New York, NY 10017

M. Prager

THE NORTON COMPANY

High Performance Ceramics Division

Goddard Road

Northborough, MA 01532-1545

N. Corbin

THE TORRINGTON COMPANY

Advanced Technology Center

59 Field St.

Torrington, CT 06790

W. J. Chmura

UNION CARBIDE CORPORATION

Linde Division

P.O. Box 44

175 East Park Drive

Tonawanda, NY 14151-0044

Harry Cheung

UNITED TECHNOLOGIES RESEARCH CENTER

MS 24, Silver Lane

East Hartford, CT 06108

K. M. Prewo

\section{UNIVERSITY OF TENNESSEE}

Dept of Materials Science and Engineering

Knoxville, TN 37996-2200

P. K. Liaw
UNIVERSITY OF WASHINGTON

Department of Materials Science and

Engineering

101 Wilson, FB-10

Seattle, WA 98195

T. G. Stoebe

VIRGINIA POLYTECHNIC INSTITUTE \& STATE

UNIVERSITY

Department of Materials Engineering

Blackburg, VA 24601

W. A. Curtin

K. L. Reifsnider

WESTERN RESEARCH INSTITUTE

365 N. 9th Street

P.O. Box 3395

University Station

Laramie, WY 82071

V. K. Sethi

WESTINGHOUSE ELECTRIC CORPORATION

Research and Development Center

1310 Beulah Road

Pittsburgh, PA 15235-5098

S. C. Singhal 
M98052754

Report Number (14)_ORNL/S4b--87-00184/07

Publ. Date (11) 199804

Sponsor Code (18) DOE/FE, XF

UC Category (19) UC-101,DOE/ER

DOE 